http://jmscr.igmpublication.org/home/ ISSN (e)-2347-176x ISSN (p) 2455-0450 crossref DOI: https://dx.doi.org/10.18535/jmscr/v7i8.114

\title{
Correlation in Between Age, Weight, Parirty, ANC Visits and weeks of Gestation of Mother and Neonatal Congenital Anomalies
}

Authors

\author{
Dr Nilesh Santaji Karpe ${ }^{1}$, Dr Dipak Ramdas Kamat ${ }^{2}$ \\ ${ }^{1}$ Asst Professor Dept of OBGY, Pravara Rural Hospital \\ ${ }^{2}$ Associate Professor Dept of OBGY, Pravara Rural Hospital \\ Corresponding Author
}

Dr Sayed Asif Umar

\begin{abstract}
Congenital anomalies leads to long-term disability. various risk factors like advanced maternal and paternal ages, parental consanguinity, teratogenic agents, like infectious agents and drugs, and nutritional deficiencies. Rubella, cytomegalovirus, varicella and toxoplasma are infectious agents that are transmitted to the fetus and cause adverse effects..

Aims and Objectives: To study the proportion of congenital anomalies at tertiary rural health care and correlation in between age,weight, parirty, anc visits and weeks of gestation of mother and neonatal congenital anomalies

Sample Size: we took a sample size of 150 patients. All neonates diagnosed with any congenital anomalies born in or coming to nicu of prh..

Results: Most of the anomolies were in the age group of 26 to 32 and in above 32 years of age there were 55 anomalies. majoriity of anomolies were in the mothers below $60 \mathrm{~kg}$ weight the mean weight of the mother was 53.2.only 41 mothers attended 3 ANC visit prior to delivery whereas 81 attended for 2 times and 48 for 1 once The number of anomalies were high in newborns with gestational age between 32-36 weeks[ 89followed by those with gestational age above 36 weeks [69Twelve newborns were of gestational age of below 32 weeks

Conclusion: Most of our babies with anomalies belonged to mothers with age above 30 years thus highlighting importance of relation in mothers age and pregnancy.
\end{abstract}

\section{Introduction}

Congenital anomalies are the developmental disorders present at birth. The prevalence and pattern of congenital anomalies varies between regions and may also vary over time. An estimated 303000 newborns die within 4 weeks of birth every year, worldwide, due to congenital anomalies.

According to the World Health Organization (WHO) document of 1972, the term congenital malformations should be confined to structural defects at birth. ${ }^{[1]}$ According to the World Health Organization (WHO) the term congenital anomaly includes any morphological, functional, biochemical or molecular defects that may develop in the embryo and foetus from conception until birth, that is present at birth, whether detected at that time or not ${ }^{(2) \text {. }}$

However, as per the more recent WHO fact-sheet of October 2012, congenital anomalies can be 
defined as structural or functional anomalies, including metabolic disorders, which are present at the time of birth. ${ }^{[3]}$ Structural malformations with other Congenital anomalies are one of the most important cause of neonatal mortality both in developed and developing countries. It accounts for $8-15 \%$ of Perinatal deaths and $13-16 \%$ of neonatal deaths in India. ${ }^{[4]}$

Congenital anomalies causes long-term disability, and have significant impacts on life of individuals, families, health-care systems, and societies all over, $90 \%$ of all infants with a serious congenital anomaly are born in middle and low-income countries, with poor economic conditions and it is very difficult to collect. Comprehensive data on congenital anomalies in these countries ${ }^{(5)}$. Various environmental factors are identified to be risk factors for congenital anomalies among infants.. most common of the risk factors include advanced maternal and paternal ages, parental consanguinity, teratogenic agents, infectious agents and drugs like thalidomide and nutritional deficiencies of iron folic acid etc ${ }^{(6,7)}$. Rubella, cytomegalovirus, varicella and toxoplasma are infectious agents that are very likely to be transmitted to the fetus from mother and cause adverse fatal effects. Maternal health conditions that contribute to increased risks for congenital anomalies include obesity, use of anticonvulsant medications during pregnancy, and insulindependent diabetes mellitus, anemia hypertension etc $^{(8,9,10)}$.

So far, very little information is available regarding the pattern and factors associated with congenital anomalies considering all this facts. This study is conducted to study the congenital anomalies in newborn and its outcome in a rural based tertiary care centre. For identifying the patterns and factors associated with congenital anomalies and its immediate outcome in neonates

\section{Aims and Objectives}

1. To study the proportion of congenital anomalies at tertiary rural health care
2. To find the correlation in between the age of mother and neonatal congenital anomalies

3. To find the correlation in between the weight of mother at the time of delivery and neonatal congenital anomalies

4. To find the correlation in between the gestational age in weeks at the time of delivery and neonatal congenital anomalies

5. To find the correlation in between the parity and ANC visits prior to delivery and neonatal congenital anomalies

\section{Materials and Methods}

Observational longitudinal hospital based study.

\section{Sample Size}

We took a sample size of 150 patients.

\section{Source of Data}

Tertiary care Rural Hospital.

\section{Selection of Cases}

All neonates diagnosed with any congenital anomalies born in or coming to NICU of PRH.

\section{Duration of Study}

2 Years (1/7/2016 TO 31/8/2018).

\section{Inclusion Criteria}

All neonates delivered in or referred to NICU of PRH with congenital malformation

All neonates diagnosed with congenital malformation whose parents or guardian are ready to give written informed consent for the study

\section{Exclusion Criteria}

Still born.

\section{Study Conduct}

Printed proforma will be used for recording thorough clinical examination of new born

Head to toe examination

Systemic Examination

Investigational Profile: List of investigations as mentioned in study proforma

Outcome Parameters:

Type of intervention done:

Surgical / Non surgical

Untreated

Status at discharge 
Statistical analysis will be done with descriptive statistics

\section{Proforma}

\section{Maternal History}

Mother's name

Age

Occupation -

Education Income

Father's name

Age Education

Occupation -

Religion Income-

Caste

Antenatal history

Registered delivery

Menstrual History

Age at menarche

cycle

LMP

EDD

Maternal risk factors

Age

Prepregnancy weight

Height

Previous abortion/ still birth

Previous neonatal death

Previous low birth weight

History of Toxaemia

Diabetes

TORCH

UTI

Fever with Type equation here.rash

Addiction smoking tobacco chewing alcohol Drugs history anticonvulsant,

Antipshychotic

Any other drug during pregnancy

Radiation

pollutants (a) mining (b)other industrial

(c) pesticides

\section{Personal History}

Water supply

housing

Income -education

Waste disposal

Family history

H/O Consanguinity 1st /2nd /3rd
Any history of cong. defects in

Siblings

Relative

Neighbour hood

History of repeated abortions

\section{Dietary History}

vegan/non vegetarian

Clinical examination of mother

Anthropometry /any malformation

Maternal investigation

Blood group

Hemoglobin \%

Routine urine examination

Yes No VDRL

HIV

Blood sugar

USG

Fetal Scan

\section{Clinical Examination of Neonate}

Term

Age

Sex

Single

twin

Mode of delivery

Vaginal

ceasarian

Apgar

Vit.k

Duration of labour

Anthrometry-

\section{Head to toe Examination of Newborn}

Skull, Eyes, Ears, Face, Nose, Oral cavity, Neck, Chest, Upper extremity, Finger Position

Lower extremity Toes, Foot

Spinal examination Continuation, Neural tube defect

\section{Systemic Examination}

Cardiovascular system, heart rate, murmur

Respiratory system Respiratory rate, Type of respiration

Abdominal examination Tendernes, organomegaly 


\section{Central nervous system examination}

Power, Cry, Muscle tone, Activity

\section{Investigation}

Complete blood count, Blood group, Blood sugar,

S. calcium, CRP

In specific condition

VDRL, TORCH titre, Karyotyping

Neurological inv.

Eeg, CT, MRI, Neurosonography, Infantogram, Invertogram, xray

\section{Observations and Results}

In the present study 170 cases newborns with congenital anomalies were studied.

Of which 106 were males and 64 were females Iin our study the percentage of male was more as compared to female

The average maternal age was 30.38 years (5).

\begin{tabular}{|l|c|}
\hline MATERNAL AGE & NUMBER OF ANOMOLIES \\
\hline $19-25$ & 28 \\
\hline $26-32$ & 87 \\
\hline ABOVE 32 & 55 \\
\hline
\end{tabular}

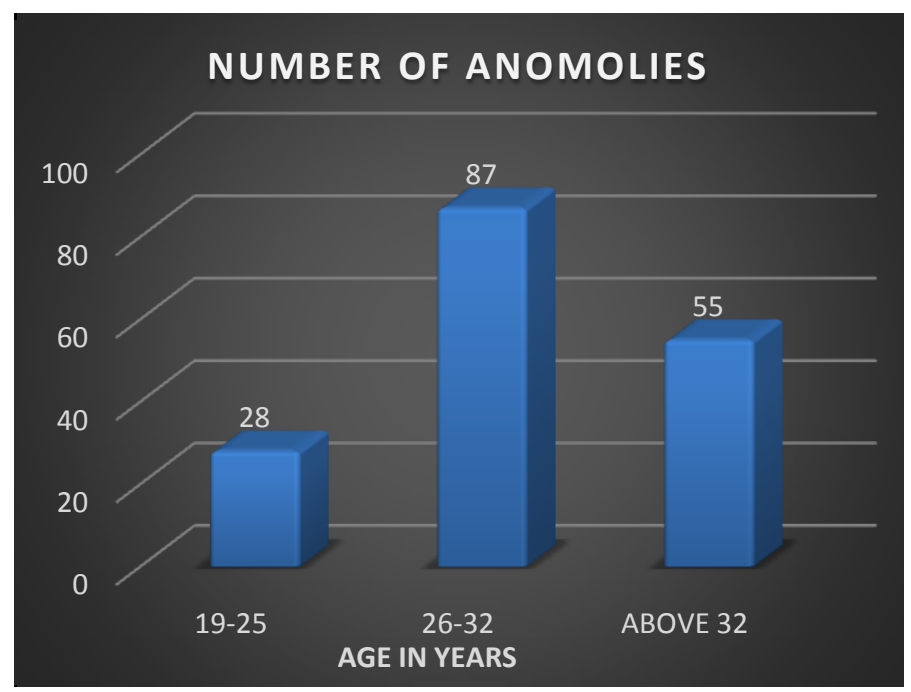

Most of the anomolies were in the age group of 26 to 32 and in above 32 years of age there were 55 anomalies the mean

Weight of the mother and the number of anomolies

The average weight of the mother in our study

was

\begin{tabular}{|l|c|}
\hline Weight at the time of delivery & NO OF ANOMOLIES \\
\hline Upto 50 & 69 \\
\hline $51-60$ & 76 \\
\hline$>61$ & 25 \\
\hline
\end{tabular}

Majority of anomolies were in the mothers below $60 \mathrm{~kg}$ weight the mean weight of the mother was 53.2

\section{NO OF ANOMOLIES}

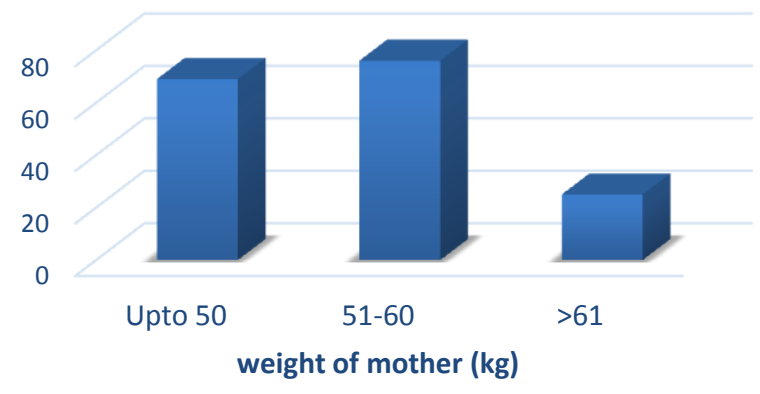

The average weight of mothers was $53.25 \mathrm{~kg}$.

\section{3] ANC visit prior to delivery}

\begin{tabular}{|l|c|}
\hline $\begin{array}{l}\text { ANC Visit prior to } \\
\text { delivery }\end{array}$ & $\begin{array}{l}\text { NUMBER OF } \\
\text { ANOMOLIES }\end{array}$ \\
\hline 1 & 48 \\
\hline 2 & 81 \\
\hline 3 & 41 \\
\hline
\end{tabular}

Only 41 Mothers Attended 3 ANC Visit Prior to delivery whereas 81 attended for 2 times and 48 for 1 time

\section{NUMBER OF ANOMOLIES}

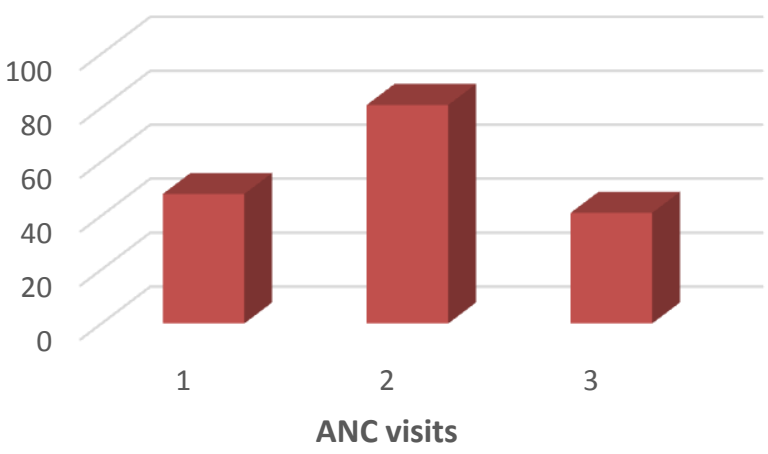

The mean ANC visits of mothers was 1.95

\section{4] Parity of mother during delivery}

Parity of mother during delivery

\begin{tabular}{|l|c|c|c|c|}
\hline P 1 & P2 & P3 & P4 & $<\mathrm{P} 4$ \\
\hline 51 & 41 & 49 & 25 & 4 \\
\hline
\end{tabular}




\section{NO OF ANOMALIES}

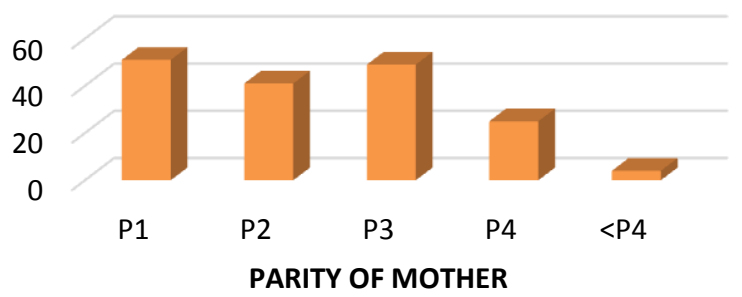

5. Distribution of anomalies according to gestational age of newborn.

\begin{tabular}{|l|c|c|}
\hline $\begin{array}{l}\text { Gestational Age } \\
\text { in weeks }\end{array}$ & $\begin{array}{c}\text { Number of newborns } \\
\text { with Anomalies }\end{array}$ & $\begin{array}{c}\text { Percentage } \\
(\%)\end{array}$ \\
\hline Below 32 & 12 & $7 \%$ \\
\hline $32-36$ & 89 & $52.35 \%$ \\
\hline Above 36 & 69 & $40.58 \%$ \\
\hline Total & 170 & $100 \%$ \\
\hline
\end{tabular}

The number of anomalies were high in newborns with gestational age between 32-36 weeks [89(52.35)] followed by those with gestational age above 36 weeks [69(40.58\%)]. Twelve newborns were of gestational age of below 32 weeks (Table no. 5\& Figure no. 5)

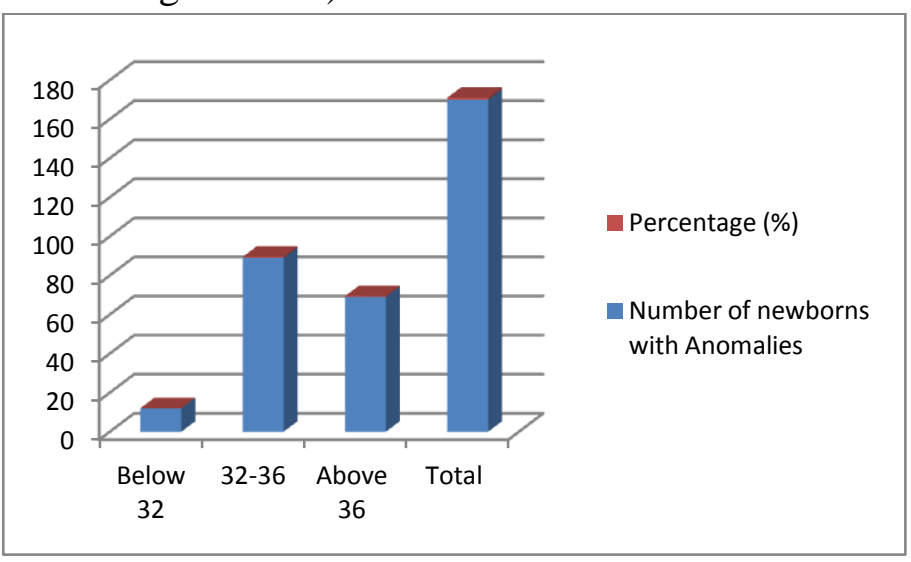

\section{Results and Discussion}

\section{Distribution of the birth Defects Diagnosed and: sex Distribution of Congenital Malformation}

Out of 170 cases of malformations, 106 were males and 64 were females of which 123 were inborn and 47 were outborn. Major Anomolies Were $91.14 \%$ and Minor Were $8.82 \%$ (Table no 1 and 2)

Total number of neonatal admissions during the period of $1^{\text {sl }}$ May 2016 to $30^{\text {lh }}$ June 2018 was
19600. Of which 17400 newborns were delivered in this hospital and 2200 newborns were referred from the community during the study period, the total inborns in the hospital were 17400. The inborns and outborns in the study were 123 and 47 respectively. Therefore, the proportion of congenital anomalies in newborns at our hospital setting is 7.06 per thousand births. The proportion of males in both inborn and outborns was proportionately higher in males, (Table no.3). The distribution of gender among inborns and outborns. ( $\mathrm{P}=0.72$, Fisher's Exact Test). Various workers have reported higher incidence of malformations in males than females: Bhat and Babuetal (1998) ${ }^{[13]}$ Misra et al (1989) ${ }^{[17]}$ S. Swain et al. (1994) $)^{[51]}$ Of which only Bhat and Babu (1998) 13] found the difference to be statistically significant (15:1).Mathur et al (1975) ${ }^{[16]}$ and Thirumalaikolundu subramanian et al $(1985)^{[21]}$ reported a Male: Female ratio of 2:1 and 1.7:1 i.e. insignificant. Infact a study by J.S. Anand $(1988)^{[12]}$ has found a greater incidence in females than males, while Verma (1991) ${ }^{[11]}$ found no difference in sex distribution. In our study the incidence is more in males.

\section{Distribution of Congenital Malformations according to maternal age and weight}

In our study of 170 babies with birth defects, 28 anomalies were present in the mother in between the age group of 19 - 25yrs and 87 anomolies were in the age group of 26 to 32 and in the number of anomalies were high in newborns with gestational age between 32-36 weeks [89(52.35)] followed by those with gestational age above 36 weeks [69(40.58\%)]. Twelve newborns were of gestational age of below 32 weeks (Table no. $5 \&$ Figure no. 5 above 32 years of age there were 55 anomalies the mean mother age in our study was 30.87 years. majority of the mothers in our study were above 32 years of age and were elderly primigravida.

Therefore the incidence of malformation was found to be higher with increasing maternal age 32 yrs. Maternal age has long been known to be 
positively associated with congenital anomalies. Most workers have found increased frequency of congenital malformations with advanced maternal age (> 35yrs) our study strongly co incides with the study done by. Patel and Adhia (2005) ${ }^{[18]}$ Swain et al (1994) $)^{[20]}$ and Grower (2000) ${ }^{[15]}$ However Verma et al (1991) ${ }^{[11]}$ and J S Anand $(1998)^{[12]}$ did not find increase in incidence with increasing maternal age.studies

\section{ANC Visit Prior To Delivery}

the mean ANC visit of the mothers with congenital anomalies in our study was 1.95 only 41 mothers attended 3 anc visit prior to delivery whereas 81 attended for 2 times and 48 for 1 time studies done by Mathur et al (1975) ${ }^{[16]}$ and Anand et al $(1988)^{[12]}$.co incides with us majority of the mothers attended either 1 or 2 ANC clinics this also indicates the poor socio economic conditions

5 Distribution of Congenital Malformation according to parity (P) of Mother:

In our study of 170 cases Majority of mothers were primipara, 51 or third para 49 , followed by second 41 and fourth para 25 and only 4 mothers were more than fourth gravida in our study incidence of congenital anomolies was more in the primigravida and the incidence was higher in the elderly primi. Several workers have reported an increased incidence of malformation with rising birth Swain et al (1994) ${ }^{[20]}$ reported significant higher $(2.03 \%)$ incidence of malformations in gravida $>4$ than babies bom to mothers of gravida $<4$ (1.04). Grover (2000) ${ }^{[15]}$ reported increased incidence of birth defects with increasing parity order but our study has adual stand in this aspect in our study anomalies are common in the elderly primi and third para . similar to our study Verma et al $(1991)^{[11]}$ in contrast J.S. Anand (1988) ${ }^{[12]}$ found $45 \%$ of malformation in primi parous. Bhat and Babu et al (1998) ${ }^{[13]}$ could not establish any correlation between incidence of congenital malformation and parity of mother

\section{Gestational age of the newborn and number of anomolies}

Out of 170 babies 12 were less than 32 wks of gestation, 89 were between 32 to $36 \mathrm{wks}$ and 69 babies were more than 36 weeks of gestation 78 were less than or equal to $101 \mathrm{wks}$ and 69 were more than 36 weeks of gestation. Our study strongly suggests that gestational age of less than 36 weeks had a strong correlation with anamoly. On comparing Age of mother with gestation age in weeks (Spearman Rank Correlation, Spearman $r=0.04123$ (corrected for ties), The two-tailed $\mathrm{P}$ value 0.5936 , considered not significant most of the studies are in accordance with us and show higher incidence of birth defects among preterm: like Bhat and Babu (1998) ${ }^{[13]}$ and J.S. Anand $(1998)^{[12]}$

\section{Conclusion}

In our study we came to acopnclusion that congenital anomolies are more common in late pregnancy early gestational age ,and they are more common in multiparous women and regular antanatal check up can reduce the proportion of congenital neonatal anomalies

\section{References}

1. World Health Organization. Section on congenital anomalies. Available from: http://www.who.int/mediacentre/factsheets /fs370/en/. [updated on 2016 sep]

2. Shawky RM, Sadik DI: Congenital malformations prevalent among Egyptian children and associated risk factors. Egyptian Journal of Medical Human Genetics 2011, 12:69-78.

3. Bhat BV, Ravikumara M. Perinatal mortality in India-Need for introspection. Indian J Matern Child Health 1996;7:31-3.

4. Agarwal SS, Singh U, Singh PS, Singh SS, Das V, Sharma A, et al. Prevalence and spectrum of congenital malformations in a prospective study at a teaching hospital. Indian J Med Res 1991;94:413-9.

5. Singh A, Gupta RK: Pattern of Congenital Anomalies in Newborn . A Hospital Based Prospective Study. JK Science 2009, $11: 34-6$ 
6. Ive C, Oliveira F, Richieri-costa A, Cristina V, Ferrarese C, Cristina D: Birth defects in newborns and stillborns : an example of the Brazilian reality. BMC 2011, 4:343.

7. Congenital Anomalies in Canada. Perinatal Health report 2002.

8. Samina Shamim, Nadeem SQC: Pattern of congenital malformations and their neonatal outcome. Journal of surgery Pakistan international. 2010, 15:34-7

9. Adam .A. Rosenberg, Henry .L. Galen; Fetal Drug Therapy; Pediatrics Clinics of North America: Feb 1997; 44(1):939-954.

10. Smith's Recognizable patterns of human malformations $4^{\text {th }}$ Ed W.B Saunders 1988

11. Verma M, Chatwal, Singh D; Congenital malformation a retrospective study of 10,000 cases: Ind Jr Pediatr 1991; 58:245252.

12. A Anand J.S., Javdekar .B.B., Belani .M; Congenital malformations in 2000 consecutive births; Indian Pediatrics: 1998, 25: $845-851$

13. Bhat .B.V., Babu .L., Congenital Malformations at birth-a prospective study from south India; Indian Journal of Pediatrics: 1998 Nov-Dee; 65(6):873-81

14. Ghosh S., Bhargav S.K; Congenital malformations in a longitudinal study of birth cohort in an urban community. Ind $\mathrm{Jr}$ Med Research 1985; 82:427-433.

15. Grover N: Congenital malformations in Shimla; Ind Jr of Pediatrics 2000 69(4): 249-251

16. Mathur B.C, Karan W.S, Vijayadevi K.K; Congenital malformations in newborn; Ind Pediatr; 1975;12:179-181.
17. Mishra P.C, Baveja R; Congenital Malformations in newborn a prospective study- Ind Pediatr 1989 Jan; 26(1):32-5.

18. Patel Z.M, Adhia R.A; Birth Defects Surveillance Study; Ind Jr Pediatr; 2005;72:489-491.I

19. Saifulla S, Chandre R.K, Pathak L.C; Congenital malformations in newborn; Ind Pediatr; 1967;4:251-26.

20. S. Swain, A. Agarwal, B.D.Bhatia; Congenial malformations at birth; Ind Pediatr; 1994; 31:1187-1191.

21. Thirumalaikolundu subramanian $P$, Jayaprakash C.A; Congenital anomalies and sex of the baby. Ind Pediatr 1975; 12:179-183.

22. Taksande A, Vilhekar K, Chaturvedi P, Jain M: Congenital malformations at birth in Central India: A rural medical college hospital based data. Indian journal of human genetics 2010, 16:159-63. 